\title{
Miradas de inspección: las bibliotecas populares del partido de La Plata según los informes de la Comisión Protectora, 1919-1945
}

\author{
Doi: $10.25100 /$ hye.v14i51.6986
}

Artículo recibido: 05-01-2018 / Artículo aceptado: 21-03-2018

\section{Ayelén Fiebelkorn}

Becaria doctoral por la Universidad Nacional de La Plata (IdIHCS-UNLP), La Plata, Argentina.

Correo electrónico: ayelenfiebelk@gmail.com

Forma de citar este artículo: Fiebelkorn, Ayelén. "Miradas de inspección: las bibliotecas populares del partido de La Plata según los informes de la Comisión Protectora, 1919-1945". Historia y Espacio, vol. 14, nº 51 (2018): 109-134. Doi: 10.25100/hye.v14i51.6986.

Artículo Tipo 1: de investigación. El presente artículo forma parte de una investigación doctoral titulada: "Sociabilidades platenses en movimiento: bibliotecas populares frente al desafío de la cultura de masas en la entreguerra” dirigida por el Doctor Andrés Bisso y co-dirigida por el Mg. Enrique Garguin. 


\section{Miradas de inspección: las bibliotecas populares del partido de La Plata según los informes de la Comisión Protectora, 1919-1945}

Resumen: Entre las décadas de 1910 y 1940 en los barrios de distintas ciudades argentinas se fundaron centenares de bibliotecas populares que obtuvieron la protección de la Comisión Protectora de Bibliotecas Populares (repartición del Ministerio de Justicia e Instrucción Pública). En el presente artículo abordaremos los distintos informes de inspección que los/as inspectores/as de dicha Comisión elaboraron a partir de sus visitas a las bibliotecas populares del Partido de La Plata (Capital de la Provincia de Buenos Aires) entre 1919 y 1945, período de expansión de la ciudad y del número de bibliotecas.

Buscando exceder -sin desatender- el plano descriptivo que este tipo de fuente documental puede brindarnos (fecha de fundación, cantidad y calidad de libros, aspecto de las salas de las bibliotecas, etc.), partimos del concepto de mirada(s), el cual nos permite atender a las atribuciones de sentidos operadas por estos/as funcionarios/as acerca de las bibliotecas populares inspeccionadas, sus contextos de inserción barrial, sus dirigentes y sus materiales bibliográficos.

Palabras clave: Bibliotecas populares, Informes de inspección, Miradas.

\section{Inspection looks: the popular libraries of the La Plata party according to the reports of the Protective Commission, 1919-1945}

Abstract: Between the decades of 1910 and 1940, in the neighborhoods of different Argentine cities, hundreds of popular libraries were founded and obtained the protection of the Protective Commission of Popular Libraries (state agency of the Ministry of Justice and Public Instruction). In this article, we will deal with the different inspection reports that the inspectors of said Commission elaborated from their visits to the popular libraries of the Party of La Plata (Capital of the Province of Buenos Aires) between 1919 and 1945, period of expansion of the city and the number of libraries.

Tryin to exceed - without neglecting - the descriptive plan that this type of documentary source can offer us (date of foundation, quantity and quality of books, aspect of library rooms, etc.), we start from the concept of look(s), which It allows us to attend to the attributions of senses operated by these officials regarding the popular libraries inspected, their neighborhood insertion contexts, their leaders, and their bibliographic material.

Keywords: Popular libraries, Inspection reports, Looks. 


\section{Ayelén Fiebelkorn}

\section{Miradas de inspección: las bibliotecas popu- lares del partido de La Plata según los infor- mes de la Comisión Protectora, 1919-1945}

\section{Introducción}

Durante las primeras décadas del siglo XX, las ciudades argentinas de la región pampeano-litoraleña experimentaron la expansión de su territorio y de su población como consecuencia de la afluencia inmigratoria de las últimas décadas del siglo XIX. En ese contexto, los/as vecinos/as de nuevos barrios urbanos y suburbanos multiplicaron los ámbitos de sociabilidad barrial, fundando centenares de clubes deportivos, sociedades y centros de fomento, asociaciones étnicas y culturales y, particularmente en los años de entreguerras (1914-1945), bibliotecas populares ${ }^{1}$.

En la ciudad de La Plata, capital de la provincia de Buenos Aires fundada en 1882, una enorme cantidad de bibliotecas se crearon, dentro de clubes y sociedades de fomento, en ese corto lapso de treinta años. Alrededor de unas quince bibliotecas lograron obtener la protección de la Comisión Protectora de Bibliotecas Populares, repartición estatal dependiente del Ministerio de Justicia

1 Véase: Luciano De Privitellio, Vecinos y ciudadanos. Política y sociedad en la Buenos Aires de entreguerras (Buenos Aires: Siglo XXI, 2003); Ricardo González, "Lo propio y lo ajeno. Actividades culturales y fomentismo en una asociación vecinal. Barrio Nazca (1925-1930)". En Mundo urbano y cultura popular. Estudios de historia social, compilado por Diego Armus (Buenos Aires: Sudamericana, 1990); Leandro Gutiérrez y Luis Alberto Romero, Sectores populares, cultura y política. Buenos Aires en la entreguerra. (Buenos Aires: Siglo Veintiuno Editores, 2007 [1995]). 
e Instrucción Pública, cuyo objetivo era garantizar el "fomento, la inspección, y la inversión de fondos" sobre este tipo de instituciones ${ }^{2}$.

Aquí abordaremos un conjunto de informes de inspección que los/as funcionarios/as de dicha Comisión elaboraron a partir de sus visitas a las bibliotecas populares en funcionamiento durante las décadas de 1920, 1930 y 1940 en el partido de La Plata. Partimos para ello del concepto de mirada, formulado por el psicoanalista Jacques Lacan -inspirado en Sartre- y retomado, desde la historia cultural, por Peter Burke ${ }^{3}$, para designar lo que antes se nombraba como punto de vista. Plasmadas en el ítem "observaciones" de los informes de inspección, las miradas de los/as inspectores/as, nos permiten exceder .el plano estrictamente descriptivo que este tipo de fuente documental puede brindarnos (cantidad de libros, mobiliario, horario de atención, nómina de autoridades de la biblioteca, etc.), para avanzar en las atribuciones de sentidos operadas por estos/as funcionarios/as de una dependencia estatal de la cultura-la Comisión Protectora- acerca de instituciones de la cultura popular sostenidas por la sociedad civil -las bibliotecas populares-.

Nuestro análisis se inicia en 1919, año en que el Presidente Yrigoyen sancionó un decreto mediante el cual amplió las atribuciones y facultades de la Comisión Protectora, y culmina a mediados de la década de 1940, cuando por un lado, en 1944, se sancionó el Decreto n. 9991 de la Ley Provincial n. ${ }^{-0}$ 4688, que puso en marcha el funcionamiento de la Dirección General de Bibliotecas la Provincia, lo cual redundó en que muchas de estas instituciones comenzaran a ser subsidiadas por el estado provincial; y por otro lado, cuando un nuevo decreto de 1946 amplió nuevamente las atribuciones y finalidades de la Comisión Protectora ${ }^{4}$.

2 Hubo otras bibliotecas de la ciudad que funcionaron dentro de clubes o sociedades de fomento, sin la protección de dicha Comisión y, lamentablemente, sin dejar rastros, a excepción de su ocasional mención en la prensa local o la persistencia en la memoria de algún/a vecino/a centenario/a.

3 Peter Burke, Visto y no visto. El uso de la imagen como documento histórico. (Barcelona: Crítica, 2005), 155-175.

4 En línea con el objetivo dinamizar la institución, en 1948 comienza a editarse la Revista de la Comisión de Bibliotecas populares, ver: Flavia Fiorrucci, "La cultura, el libro y la lectura bajo el peronismo: el caso de la Comisión de bibliotecas populares". Desarrollo Económico, Vol. 48, n⿳⺈ 192, (enero-marzo, 2009): 543-556. 


\section{Enfocar la mirada: los términos de la relación entre la Comisión Protecto- ra y las bibliotecas protegidas}

En diciembre de 1919, Manuel Borton, Inspector de la Comisión Protectora de Bibliotecas Populares (CP, de ahora en adelante), viajó a la ciudad de La Plata para inspeccionar el funcionamiento de la Biblioteca y Centro Social "Vicente de Tomaso". El procedimiento era de rigor: como funcionario de la CP, Borton había acudido a numerosas bibliotecas de lejanas localidades del país; más aún, no era la primera vez que se apersonaba en esta pequeña salita del barrio ferrioviario de Tolosa, en las afueras de la ciudad.

El nombre de la biblioteca, "Vicente de Tomaso", homenajeaba a un obrero socialista muerto a manos de un militante radical cuando, en plena campaña electoral, pegaba carteles de propaganda partidaria en las calles de Buenos Aires, en febrero de $1918^{5}$. La institución había sido fundada apenas tres meses después del asesinato del obrero socialista, un 2 de mayo de 1918, por un grupo de jóvenes vinculados al Partido Socialista local.

Al día siguiente de efectuada su visita, el Inspector Borton escribió, de puño y letra, el informe correspondiente, dirigido al Presidente de la CP:

La biblioteca es de muy poca importancia y los socios que he conocido son muchachos obreros en su mayoría (...) Tienen una compañía infantil entre sus asociados para hacer comedias, pero el rendimiento de sus éxitos debe ser muy precario porque andan los actores muy mal vestidos. No me explico el interés por los libros de esta pobre gente. Esta asociación no comprará jamás libros de acuerdo con la Ley de Bibliotecas de $1870^{6}$.

Esta última alusión del Inspector acerca de la compra de libros se vincula con lo establecido por la Ley 419 -de "protección y fomento a las bibliotecas populares"- (1870): la CP otorgaba una cuota igual al dinero recolectado por cada biblioteca y el importe de ambas contribuciones se invertía en libros. Es decir, las bibliotecas protegidas no recibían dinero en efectivo de la CP, sino un saldo a favor para adquirir material bibliográfico que necesitaran ${ }^{7}$-y que la

5 Los hechos fueron titulados por la prensa local como "La lucha del engrudo": "La riña que se trabó entre ambos por cuestiones electorales terminó a balazos, resultando muerto Vicente de Tomaso", en El Argentino, 28 de mayo de 1918, p. 4.

6 Expediente n⿳⺈ 326-L-18, Informe de Inspección, 16/12/1919, Comisión Nacional de Bibliotecas Populares (CONABIP de ahora en adelante).

7 Javier Planas, Libros, lectores y sociabilidades de lectura. Una historia de los orígenes de las bibliotecas en la Argentina (Buenos Aires: Ampersnad, 2017), 42-43. 
Comisión conseguía a un precio mayorista-, además de frecuentes donaciones de libros ${ }^{8}$.

El lapidario informe labrado por Borton mereció una escueta respuesta al llegar a manos del Presidente de la CP, Miguel F. Rodríguez, quien contestó: "Vuelva a la inspección para que informe si la biblioteca funciona en conformidad a las disposiciones legales, pues eso es lo que importa”. De modo que, dos días más tarde, el Inspector Borton se vio compelido a precisar su informe: "No tienen estatutos, ni tienen dinero según ellos mismos para comprar libros por nuestro intermedio de acuerdo a la Ley Sarmiento" ${ }^{10}$.

Así, en pocas palabras, la intervención del Presidente de la CP esclareció los límites de la labor del Inspector, no haciendo lugar a sus juicios individuales y oponiendo a ellos la letra de la ley. En parte, su actitud puede explicarse por el hecho de que la oficina a su cargo transitaba años de inusitado activismo. En efecto, desde su creación en 1870, la actuación de la Comisión Protectora de Bibliotecas Populares, dependiente del Ministerio de Justicia e Instrucción Pública, había sido sumamente discontinua: funcionó activamente entre 1870 y $1876^{11}$, año en que se suprimió por falta de fondos; y recién en 1908 fue reabierta, por iniciativa del Presidente Figueroa Alcorta, iniciando un período de actividad estable, aunque siempre dependiente del (variable) presupuesto anual asignado por el Congreso Nacional ${ }^{12}$. En ese marco de creciente activismo, en marzo de 1919, el Presidente Yrigoyen sancionó un decreto mediante el cual

8 Es interesante señalar que los términos de la protección no siempre estaban claros para los propios dirigentes de las bibliotecas. En 1920, por ejemplo, la recientemente fundada Biblioteca Popular Alejo Iglesias, del barrio suburbano de Villa Elisa, solicitaba a la CP "un subsidio de $\$ 500$ anuales" ya que con el "modesto aporte" de sus asociados no podía aumentar las comodidades de la institución ni adquirir nuevas obras, recibiendo por respuesta que "la Comisión no posee facultades legales para acordar subsidios en dinero y que esto debe pedirse al H. Congreso de la Nación por nota”, ver: Expediente n⿳⺈ 342-V-20, "Nota al Presidente de la CP”, 30/9/1921, CONABIP.

9 Expediente n⿳⺈ 326-L-18, 29/12/1919, CONABIP.

${ }^{10}$ Ibíd, 31/12/1919.

11 Para un análisis de estos primeros años de actuación de la Comisión y la expansión de bibliotecas populares a partir de la Ley 419 de 1870, remito a: Javier Planas, "Libros, lectores y sociabilidades".

12 Por ejemplo, entre los años 1931 y 1938, la CP sufrió un brusco descenso presupuestario: "Las sumas variables hasta entonces asignadas a la CP en las leyes de gastos anuales, quedaron convertidas, a partir de 1931, en una partida fija, sensiblemente disminuida”, explicaba hacia 1938 su entonces Presidente Juan Pablo Echagüe en "Viven una existencia firme y próspera las bibliotecas populares”, La Nación, 19 de febrero de 1938, p. 6. 
se amplificaron las atribuciones de la $\mathrm{CP}^{13}$ y se establecieron los requisitos que las bibliotecas debían cumplimentar para solicitar la protección de la misma. Organizados en cinco ítems, estos consistían en que las bibliotecas protegidas garantizaran el libre acceso de cualquier individuo y dispusieran de un local abierto al menos doce horas semanales -diurnas o nocturnas, continuas o discontinuas-y los días feriados por lo menos tres horas por la tarde. Asimismo, las autoridades de la asociación debían responsabilizarse por los libros que se le entregaran o por su valor de compra; y por último, debían someterse a la inspección y contralor de la CP acatando sus resoluciones.

A los fines del presente análisis, este último punto cobra centralidad: los informes de inspección, si bien ya existían, se tornarían en esta etapa expansiva de la CP una herramienta clave a los efectos de constatar que las bibliotecas funcionaran, al decir de Rodríguez, "en conformidad a las disposiciones legales". La tarea de inspeccionar bibliotecas no solo estuvo a cargo de los/as inspectores/ as de la $\mathrm{CP}$, que contaba con un escaso número de empleados/as, situación que motivaba el permanente reclamo del Presidente de la CP al Ministro para que la dependencia obtuviera "un presupuesto acorde a sus necesidades"14. Según el mismo decreto de 1919, los Rectores de Colegios Nacionales y Directores de Escuelas Normales quedaban obligados a inspeccionar las bibliotecas si la Comisión así lo solicitase, al igual que los jefes de Reparticiones Nacionales debían "suministrar cualquier información que se les solicite"15.

Con todo, aquí consideramos los informes elaborados por tres inspectores y una inspectora de la CP (y no los remitidos por Rectores o Jefes de Correo, los cuales se limitaban a completar los ítems solicitados y no contenían observaciones), en funciones entre los años 1919 y 1945 . En líneas generales, y salvo pequeñas variaciones, aquellos informes mantuvieron un mismo formato estandarizado, como veremos en el siguiente apartado.

13 "La CP fundará a medida que lo permitan sus recursos, bibliotecas populares en todas las poblaciones o barrios, que no tengan ninguna, siempre que se constituya una Comisión Vecinal y se disponga de un local aparente (...)", Fragmento del Decreto del 31 de marzo de 1919, en Expediente n. ํㅜ 423-E-30, CONABIP.

${ }^{14}$ En las memorias de la CP, Rodríguez argumentaba que "no hay proporción entre el número de empleados superiores y el número de empleados inferiores, siendo muy escaso este para la tarea continua, y en cierto modo, detallista, de los servicios que presta esta repartición", en Memoria de la Comisión Protectora de Bibliotecas Populares de los años 1915 y 1916 (Buenos Aires: Talleres Gráficos de L.J. Rosso y Cía, 1917), 3.

${ }^{15}$ Fragmento del Decreto del 31 de marzo de 1919, en Expediente n. ${ }^{\circ}$ 423-E-30, CONABIP. 
Pero de momento, volvamos a la biblioteca "Vicente de Tomaso" inspeccionada por Borton. Durante el año 1920, el Secretario de la biblioteca agradeció por correspondencia al Presidente de la CP el frecuente envío de remesas de libros, a la par que solicitó "libros de cuentos infantiles para formar una biblioteca infantil, manuales de artes y oficios, libros de autores como Alberdi o Agustín Álvarez, autor muy conocido en esta ciudad"16.

Esta correspondencia nos permite asumir que, pese al ofensivo informe de Borton, la relación entre los dirigentes y el Presidente de la CP se tradujo en una sostenida cordialidad, al menos hasta el día en que el Inspector Borton volvió a acudir a la sala de la biblioteca:

Por fin he encontrado abierta sus puertas a las nueve de la mañana del domingo 27 del actual [febrero 1921] y he podido hablar con uno de sus socios, pero me ha sido imposible con el Secretario General (...) pues se negó a concurrir sabiendo que yo estaba, y mandó las llaves donde están los libros. Es misteriosa la conducta de esta gente: esta es la sexta vez que intento visitar esta biblioteca y la primera vez que consigo entrar (...) La biblioteca no puede ser más insignificante: un pequeño armario con 400 volúmenes (...) gran parte de ellos folletines y revistas. Nunca han comprado libros porque jamás tienen con qué según mi propio informante. No hay estatutos ni apuntación de ninguna clase de donde poder sacar datos estadísticos (...) He permanecido desde las nueve hasta las once de la mañana y nadie entró a leer en su local. Esto es también el centro político socialista y cuenta con 61 afiliados que sostienen la biblioteca, con la contribución de treinta centavos mensuales cada uno. Esto es todo lo que hay ${ }^{17}$.

Este nuevo informe del Inspector condujo a la "suspensión del envío de libros". Se trataba de una típica sanción de la CP frente a una inspección desfavorable; en tal caso las bibliotecas eran notificadas y se les otorgaba un plazo de dos o tres meses para su reorganización reglamentaria; caso contrario, corrían el riesgo de quedar "eliminadas". Pero frente a la desfavorable notificación, el Secretario de la biblioteca en cuestión, Juan Tadei, se permitió responder al Presidente Rodríguez bajo la forma de un extenso descargo:

Tal actitud [suspender el envío de libros] de la Comisión que usted tan dignamente preside no nos sorprende (...) por cuanto sabemos que es obra

${ }^{16}$ Expediente n. ${ }^{-326-L-18, ~ S o l i c i t u d ~ d e ~ m a t e r i a l ~ b i b l i o g r a ́ f i c o, ~ 1 / 9 / 1920, ~ C O N A B I P . ~}$

${ }^{17}$ Expediente n. ${ }^{3}$ 326-L-18, Informe de inspección, 21/2/1921, CONABIP. 
de un señor cuyo criterio, según lo ha demostrado, no es lo suficientemente abierto como para respetar ideas ajenas ${ }^{18}$.

Acto seguido, Tadei exponía detalladamente los antecedentes del "progreso evolutivo de la biblioteca" y su "estado actual": abría sus puertas todos los días de 20 a 22 hs y los domingos de 9 a 12 hs; poseía más de mil libros, recibía distintas revistas; y no solo registraba una numerosa concurrencia de lectores, sino que también se impartían en su pequeña sala cursos nocturnos gratuitos de música, inglés, taquigrafía, aritmética y castellano. Aquel estado de cosas correspondía a la labor tenaz y entusiasta de los asociados a lo largo de tres años consecutivos, en los cuales

La lucha que ha tenido que sostener nuestra biblioteca ha sido difícil, dadas las condiciones económicas con que siempre ha tenido que tropezar. Bien sabe el señor Presidente que este es un mal que se observa en la mayoría de las instituciones nuevas y especialmente de un carácter esencialmente popular $(\ldots)^{19}$.

El comentario de Tadei no asume un carácter excepcional a la luz de documentos de distintas bibliotecas populares en los cuales arrecian las quejas sobre las permanentes dificultades económicas. En efecto, un ítem a completar en los informes de inspección correspondía a los "Recursos con los que se sostiene la institución”. En ese campo, la respuesta solía ser idéntica: cuotas de asociados/as -promediando las bibliotecas entre 100 y 300 personas-, festivales y donaciones.

$Y$ es que en el caso argentino, las bibliotecas populares eran fundadas, administradas y sostenidas por un grupo de vecinos/as nucleados en una determinada asociación (clubes, sociedades de fomento, asociaciones culturales, etc.). Este fuerte peso de la sociedad civil encuentra su origen en la propia Ley 419 de "Fomento y Protección a las Bibliotecas Populares", impulsada por Sarmiento y sancionada durante su presidencia en septiembre de 1870. Como ha indicado Javier Planas, la Ley 419, inspirada en el modelo norteamericano de Horace Mann, radicó la iniciativa y el control de la administración de bibliotecas en las asociaciones de la sociedad civil, fomentando el "poder creativo" de esta

\footnotetext{
${ }^{18}$ Ibíd, Nota al Presidente, 16/4/1921, CONABIP.

${ }^{19}$ Ibíd
} 
y reduciendo la injerencia del Estado a las funciones de fomento, subvención e inspección, a través de la Comisión Protectora de Bibliotecas Populares ${ }^{20}$.

El largo descargo escrito por Tadei en 1921 resulta, en este sentido, un eficaz testimonio de la coordinación comunitaria que implicaba la fundación y el funcionamiento de una biblioteca barrial: disponer de un local físico (por lo general, alquilado) y amoblarlo; solicitar donaciones de libros y subsidios, escribir estatutos y reglamentos, armar los catálogos, emprender una conscripción de socios, organizar otro tipo de actividades culturales; y, al mismo tiempo, financiar lo enumerado, centralmente mediante las cuotas de asociados, pero también mediante festivales, kermeses, veladas, concursos.

Por otra parte, una prioridad ineludible para la CP consistía en que la biblioteca fuera pública -en el sentido de garantizar el acceso de cualquier individuo $^{21}$ - y así se encargaba de asentarlo el propio Tadei:

La entrada a cualquier persona es libre, siempre que vayan con el deseo de aprovechar el tiempo, leyendo cualquier libro. A pesar de esto, el señor Borton se permite decir que nuestra biblioteca no era pública sino para obreros y que a ella no podían concurrir otras personas (...) Porque el señor Borton vio en nuestro local diarios obreros, nos tildó de socialistas o anarquistas (para el caso es lo mismo) vale decir enemigos de los intereses de la patria, según él y que nosotros denominamos de otra manera. Nuestra obra dice lo contrario ${ }^{22}$.

En respuesta, el Presidente Rodríguez volvió a esclarecer, una vez más, las prioridades institucionales de la dependencia a su cargo:

Esta Comisión tiene la más buena voluntad para proteger las bibliotecas y, principalmente, aquellas que abran las puertas a los obreros, porque estos necesitan más la acción de la instrucción pública. La medida de suspender el envío de libros se ha tomado porque la biblioteca no aparece funcionando regularmente, pero esta oficina la hará inspeccionar nuevamente por si se han modificado sus condiciones y si así fuere, no habría inconveniente en dejar sin efecto la resolución tomada ${ }^{23}$.

${ }^{20}$ Ver: Planas, "Libros, lectores y sociabilidades de lectura”, 29-47.

${ }^{21}$ Es preciso aclarar que pública no se refiere a que esté legislada y financiada por el Estado -como en el caso efectivo de las "Bibliotecas Públicas"- sino que alude, en estos años, a que estén abiertas a todo público, sin exclusión alguna.

22 Expediente n. ${ }^{-}$326-L-18, Nota al Presidente, 26/4/1921, CONABIP.

${ }^{23}$ Respuesta a la Nota, 24/5/1921, CONABIP. 
Los motivos de la suspensión no eran entonces ideológicos, como presuponía Tadei a partir de los comentarios de Borton, sino estrictamente administrativos, según Rodríguez. En esta dirección, un dato sugerente es que, en medio del conflicto, precisamente en marzo de 1921, los dirigentes de la biblioteca se reunieron en Asamblea Extraordinaria y, en lo que podríamos considerar con De Certeau una táctica ${ }^{24}$, cambiaron el nombre de la biblioteca, que recordaba al militante asesinado, por el de "Alborada".

La suerte de "Alborada" fue adversa por un tiempo, y las relaciones con la $\mathrm{CP}$ sufrieron sus vaivenes - por ejemplo una nueva visita de Borton quien encontró a la biblioteca sin funcionar- hasta que, en 1924, la institución se mudó a un nuevo local, renovó sus autoridades, y recibió la visita de un nuevo funcionario. Se trataba del Inspector Albarracín, quien la encontró "completamente reorganizada y funcionando en muy buenas condiciones", en un amplio y cómodo local alquilado a la Asociación Ferrocarrilera Mutua. Luego de informar que "Alborada" reunía más de setecientos libros y folletos, impartía numerosos cursos gratuitos por las noches, Albarracín concluía:

En resumen, Señor Inspector General, creo que esta Biblioteca Popular, que hoy se ha apartado por completo de la política, ha tornado al buen camino, y, en consecuencia, se ha hecho acreedora de la protección de nuestra Oficina por funcionar de acuerdo con las disposiciones legales sobre la materia ${ }^{25}$.

Este informe favorable elaborado por Albarracín tuvo como consecuencia la reanudación y estabilización de las relaciones entre la ahora Biblioteca Popular "Alborada" y la CP, luego de una inicial etapa turbulenta (entre 1918 y 1924).

A modo de conclusión del presente apartado, destaquemos que de los intercambios epistolares entre el Inspector de la CP, el Secretario de la biblioteca, y el Presidente de la CP pueden desprenderse diversas consideraciones caras a la biblioteca y a la propia $\mathrm{CP}$-por ejemplo, las tensiones y diferencias de criterios habilitados entre el Presidente y el Inspector-, pero aquí solo nos detendremos en una de índole relacional y general: las imbricaciones entre la política, la biblioteca y el Estado.

"Vicente de Tomaso" engrosa la larga lista de bibliotecas barriales del período de entreguerras fundadas y sostenidas por militantes del Partido

${ }^{24}$ Michael De Certeau, La invención de lo cotidiano 1. Artes de hacer. (México: Universidad Iberoamericana, 2018), 40-48.

${ }^{25}$ Expediente n. ${ }^{3}$ 326-L-18, Informe de inspección, 22/5/1924, CONABIP. 
Socialista ${ }^{26}$ (o bien, por simpatizantes vinculados a la esfera cultural de dicho partido ${ }^{27}$ ). Aquella filiación o afinidad partidaria generó un manifiesto rechazo del Inspector Borton, confirmado luego por la aclaración de Albarracín ("ha tornado al buen camino"), aunque no aparecía como un factor considerable para el Presidente Rodríguez, quien, según se desprende de sus intervenciones públicas, se atenía al cumplimiento o incumplimiento de las disposiciones legales vigentes al momento de decidir acerca de las actuaciones de la $\mathrm{CP}$.

Más allá de esto, el cambio de nombre de la biblioteca "Vicente de Tomaso" por el de "Alborada", puede interpretarse como una respuesta de sus dirigentes a los informes desfavorables formulados por el Inspector Borton, una táctica en pos de diluir, ante la mirada descalificadora del Inspector, aquella identidad socialista y vindicativa que evocaba su nombre.

Este movimiento táctico de parte de los dirigentes de la biblioteca frente a la presencia real de la CP que corporizaba Borton-independientemente de que el criterio fuese o no compartido por el Presidente de la CP-, resulta por demás sugerente, pues durante la década de 1920, tal como ha comprobado De Privitellio, un alto porcentaje de asociaciones barriales rehuyeron a las definiciones político-partidarias, proclamándose como "apolíticas", en función de atraer al vecindario - conviene recordar que de ello dependía su sostén- ${ }^{28}$. De hecho, lo anterior solía aparecer expresado en los estatutos fundacionales, tal como en 1920 lo expresaba el cuarto artículo del Estatuto de la "Biblioteca Villa Elisa”: "La institución observará absoluta prescindencia en política y religión (...)" 29 .

Por último, no podríamos deducir, a partir de este "movimiento táctico", la dilución de las tendencias socialistas en el seno de "Alborada" -las cuales probablemente continuaran existiendo ${ }^{30}$ - sino más bien un modo diferente de posicionarse en la esfera pública, fundamentalmente ante el Estado y ante el vecindario.

\footnotetext{
${ }^{26}$ Ver: Dora Barrancos, La escena iluminada. Ciencia para trabajadores, 1890-1930 (Buenos Aires: Plus Ultra, 1996).

27 Tal como en el caso de la Biblioteca Juan B. Justo de la ciudad de Tandil, ver: Ricardo Pasolini. "Entre la evasión y el humanismo. Lecturas, lectores y cultura de los sectores populares: la biblioteca Juan B. Justo de Tandil, 1928-1945”. Anuario del IEHS, n.ํำ (1997): 449-474.

${ }^{28}$ Luciano De Privitellio, "Vecinos y ciudadanos”, 134-147.

${ }^{29}$ Expediente n. ${ }^{\circ}$ 342-V-20, "Estatutos y Reglamentos", 1920, CONABIP.

${ }^{30}$ La elección de un nombre como "Alborada" -y no, por caso, el de un héroe patrio-, puede ser interpretada como la continuidad de la adhesión al ideario socialista.
} 


\section{Las miradas acerca de los barrios donde funcionaban las bibliotecas y las sanciones}

Como adelantamos, durante la década de 1920, como consecuencia de la expansión de la $\mathrm{CP}$ y de las bibliotecas populares a lo largo y ancho del territorio nacional, los informes de inspección se fueron estandarizando hasta convertirse en una planilla donde los/as inspectores/as debían volcar un conjunto de datos específicos tales como fecha de fundación y asociación de pertenencia de la biblioteca, descripción de las salas de lectura (medidas, muebles y útiles) y del material bibliográfico (cantidad de libros y clasificaciones), nombres de los integrantes de la Comisión Directiva, horario de atención, recursos con los que se sostenía, número de lectores, si se indicaba con un cartel que la institución era pública, si tenía bibliotecario rentado. Solo el ítem final de estos informes, titulado "Observaciones", permitía a los/as inspectores/as extenderse en comentarios que juzgaran de interés, constituyéndose como el único espacio en el cual estos/as volcaron sus miradas acerca de, por ejemplo, los barrios en los que funcionaban las bibliotecas populares:

Está ubicada en un barrio muy apartado denominado La Loma, con calles sin adoquinar, sus servicios son de verdadera utilidad a un vecindario formado por gentes modestas, en su mayoría obreros y empleados. Concurren a ella alumnos de la escuela cercana, alumnas de los cursos que se dictan en la biblioteca y vecindario en general ${ }^{31}$.

La descripción alude a la biblioteca popular “Joaquín V. González”, fundada en 1933 por el Club deportivo Liverpool. Su autora es la Inspectora María Josefa Antelo, quien supo ser encomendada por la CP al partido de La Plata durante la década de 1930, visitando una decena de bibliotecas. A diferencia de los años de actuación del Inspector Borton (1910-1922), durante los años de desempeño de Antelo, la cantidad de bibliotecas protegidas en la región se había expandido enormemente ${ }^{32}$. Desde luego, no se trataba de un fenómeno

${ }^{31}$ Expediente n. ํㅜ 264-L-33, Informe de Inspección, 7/10/1935, CONABIP.

${ }^{32}$ Entre 1920 y 1935, en el Partido de La Plata recibieron protección de la CP: Biblioteca Popular (BP de ahora en más) Alejo Iglesias (1921) del Centro Social Villa Elisa; BP del Club Atlético y Cultural YPF (1926); BP Mariano Moreno del Centro de Fomento M. Moreno (1928); BP Bartolomé Mitre (1929) del Circulo Ensenadense de Ajedrez; BP Joaquín V. González (1933) de la Asociación Atlética Liverpool; BP Nicolás Avellaneda (1933) del Centro de Fomento y Cultura Circunvalación. No se descarta la posibilidad de que surjan otras bibliotecas populares en el transcurso de nuestra investigación. 
regional sino que un similar incremento se advierte a nivel nacional: si en 1916 la CP protegía 522 bibliotecas, en 1939 el número había ascendido a unas 1300 instituciones ${ }^{33}$.

Tal incremento obedece, entre otros fenómenos, a la expansión demográfica de los centros urbanos ${ }^{34}$ y el consecuente surgimiento de barrios periféricos, donde los/as vecinos/as creaban sociedades de fomento o asociaciones vecinales para gestionar demandas ante el municipio -agua, luminarias, transportes, etc.-; $\mathrm{y}$, de igual modo, clubes o asociaciones deportivas destinadas a la promoción de la cultura física, siendo altamente popular la práctica de futbol ${ }^{35}$.

Con el objetivo de "perseverar en la educación común y propender al desarrollo del libro en su faz moral y colectiva”, el Centro de Fomento y Cultura Circunvalación, fundaba en 1933 su biblioteca, visitada por Antelo dos años más tarde:

Situada en un apartado barrio denominado Circunvalación, en el deslinde de la ciudad de La Plata, sin medios de comunicación, por sus calles sin pavimentar. Su labor cultural es realmente beneficiosa a un barrio muy pobre; pero bastante poblado, formado por gentes modestas en su mayoría obreras $^{36}$.

De modo similar, Antelo describía como "sentida” la obra cultural realizada por la biblioteca "Mariano Moreno", la cual funcionaba en una humilde casilla de "zinc y madera (...) un tipo de edificación corriente en zonas portuarias" ${ }^{37}$. Así, en línea con las declaraciones de Rodríguez acerca de la acción prioritaria de las bibliotecas en contextos obreros, en las "observaciones" de sus distintos informes, la Inspectora se esforzaba por describir con cierto detenimiento los barrios donde estas se insertaban, en pos de ponderar su acción social. Al mismo tiempo, en su esfuerzo por traducir lo observado, sus palabras traslucen la distancia cultural existente entre ella y las "gentes modestas" de los barrios obreros.

33 El Diario, 28 de noviembre de 1939, 35.

${ }^{34}$ Para el caso de las bibliotecas de la segunda ciudad del país, Rosario (Provincia de Santa Fe), puede consultarse: Diego P. Roldán, La invención de las masas. Ciudad, corporalidades y culturas. Rosario, 1910-1945 (La Plata: Universidad Nacional de La Plata, 2012), 173-191.

35 Ver: Julio Frydenberg, Historia social del futbol: del amateurismo a la profesionalización (Buenos Aires: Siglo XXI, 2013).

${ }^{36}$ Expediente n. ${ }^{\circ}$ 177-L-33, Informe de inspección, 11/10/1935, CONABIP.

${ }^{37}$ Expediente n. ${ }^{\circ}$ 476-D-18, Informe de inspección, 10/10/1935, CONABIP. 
Como cabía a su función, la Inspectora consignó por escrito al Presidente de la CP -Juan Pablo Echagüe desde 1931- que las mencionadas bibliotecas funcionaban de acuerdo a las disposiciones vigentes. Pero no siempre las instituciones salían airosas de las visitas: dos años más tarde, Antelo repetía su visita a la biblioteca Joaquín V. González "encontrándola sin funcionar" debido a que, según le había informado uno de los vocales, la asociación se estaba instalando en un nuevo local. En consecuencia, la Inspectora observaba en su informe que:

La instalación [de la biblioteca] en una habitación interior es provisoria y completamente inapropiada por falta de espacio y su difícil acceso. Piensan trasladarla definitivamente a una de las habitaciones principales. Una vez terminada esa tarea se abrirá al público en las condiciones exigidas por la ley (...) En consecuencia, deberá SUSPENDERSE EL ENVÍO DE $\underline{L}$ IBROS y acordarse un plazo de dos meses para su reorganización ${ }^{38}$.

Idéntica sanción, aquel mismo día, recibió la biblioteca del barrio Circunvalación, pues también Antelo la encontró sin funcionar:

Según me informa el señor Secretario, desde hace tres meses ha dejado de abrirse al público, por falta de bibliotecario, atendiéndose solo el préstamo de obras a sus socios. Como el registro de obras estaba en forma deficiente, están procediendo a un nuevo recuento y a la formación de un nuevo catálogo ${ }^{39}$.

También en sus informes los/as inspectores/as solían indicar inconvenientes que derivaban en un llamado de atención de la CP. Por ejemplo: la biblioteca Bartolomé Mitre del Círculo Ensenadense de Ajedrez funcionaba en una sala de 6x5 metros con salida a un gran salón de actos, el cual derivaba en una escalera conducente a la calle. Para el Inspector Washington de la Peña, quien visitó la institución en 1945, si bien esta funcionaba de acuerdo a las normas legales y reglamentarias vigentes, su locación no resultaba suficientemente accesible:

Considero no bien cumplido el inciso a) del art. 4 del decreto de 1919, si bien compruebo que la ubicación de la biblioteca no puede ser mejorada allí.

38 Expediente n. ${ }^{\circ}$ 264-L-33, Informe de Inspección, 29/10/1937, CONABIP.

${ }^{39}$ Expediente n. ${ }^{\circ}$ 177-L-33, Informe de inspección, 29/10/1937, CONABIP. 
He visto: libro de actas, inventarios, ficheros. El registro de lectores, en el local y fuera de él es llevado en forma de boletas en duplicado. Aconsejé llevar los libros respectivos (...) En resumen: una biblioteca mediocre que no ha progresado en relación a sus años de existencia ${ }^{40}$.

Ante tal informe, la CP notificó a la entidad acerca de la conveniencia de salvar las desventajas en el lapso de tres meses. Con todo, en los años sucesivos la biblioteca continuó siendo protegida, aún cuando el mismo Inspector persistiera en opiniones desfavorables. En suma, se advierte que este tipo de observaciones desfavorables consignadas por los/as inspectores/as en sus informes, cuya usual sanción consistía en la suspensión del envío de libros por un par de meses, no atentaron contra la protección de la CP hacia las bibliotecas en cuestión.

\section{Las miradas sobre los dirigentes de las instituciones}

Otro de los centros gravitatorios de las miradas de los/as inspectores/ as, plasmadas en las "observaciones" de sus informes, se vinculaba con los dirigentes de las asociaciones que patrocinaban las bibliotecas. Dirigentes varones por regla general, en muchos casos inmigrantes e hijos de inmigrantes, con frecuencia profesionales, comerciantes y empleados, quienes en su carácter de mediadores culturales, conformaron una "elite barrial" ${ }^{41}$, y de quienes los/as inspectores/as solían destacar el acendrado entusiasmo de su accionar cotidiano, tal como se advierte en el ejemplo narrado por el Inspector Washington de la Peña:

[Ellos] exponen libros en las vidrieras de las casas de comercio, con cartones en los que han fijado interesantes leyendas alusivas a la biblioteca, a la gratuidad de sus servicios y al beneficio común de la cultura pública ${ }^{42}$.

La biblioteca popular Alejo Iglesias de Villa Elisa, contaba, según las observaciones del Inspector Albarracín, con dirigentes "muy activos a pesar de la indolencia de la mayoría de la población” ${ }^{3}$. La biblioteca Alborada, para el mismo Inspector, además de bien atendida, poseía una "muy honesta

\footnotetext{
${ }^{40}$ Expediente n. ${ }^{\circ}$ 182-E-30, Informe de Inspección, 12/06/1945, CONABIP.

${ }^{41}$ Ver: Gutiérrez y Romero, “Sectores populares”, 80-82.

${ }^{42}$ Expediente n. ${ }^{0}$ 387-L-37, Informe de inspección, 7/7/1945, CONABIP.

${ }^{43}$ Expediente n. ${ }^{\circ}$ 342-V-20, Informe de inspección, 3/4/1928, CONABIP.
} 
administración” ${ }^{44}$. Similar opinión merecía, a Albarracín, la biblioteca "Mariano Moreno", la cual “está bien atendida y mejor administrada”" años más tarde, por las observaciones de su colega De la Peña:

Hablé con cinco miembros de la CD y todos ellos demostraron interés y cariño por la biblioteca, y aunque personas sin relieve intelectual tienen el conocimiento intuitivo de la acción social de la biblioteca. En algo menos de media hora de mi visita, vi el movimiento efectivo de la biblioteca, en una noche muy fría, en aquel barrio de edificaciones humildes y espaciadas. En resumen: una humilde biblioteca a la que es preciso ayudar ${ }^{46}$.

Estas observaciones del Inspector remiten a una formulación filantrópica según la cual la "humilde" institución debía ser "ayudada" por la CP. Sus dirigentes, hombres del pueblo, poseían un conocimiento práctico de la biblioteca, alejado del saber especializado que, en materia bibliotecológica, corporizaban los/as propios inspectores/as de la CP, quienes no se limitaban a recoger los datos requeridos para completar los informes, sino que transmitían a estos dirigentes indicaciones sobre el modo correcto de llevar el registro de lectores o de completar las planillas, tal como sugiere la observación de Antelo:

La organización es muy elemental, lo que motiva que sus planillas carezcan de datos. He hecho las debidas indicaciones las que espero serán tomadas en consideración ya que sus dirigentes tienen empeño en formar una biblioteca útil y bien atendida ${ }^{47}$.

Si los elencos dirigentes solían ser entusiastas y se empeñaban por expandir los alcances de la biblioteca, hubo también excepciones. Según De la Peña, la CP debía interrogar a la Biblioteca Mitre acerca de "los medios de propaganda que emplea la CD [Comisión directiva] para despertar el amor a la lectura como base de la cultura pública”, pues "más que una biblioteca para el pueblo, parece ser solo la biblioteca de un club" ${ }^{48}$.

En las antípodas, en sus observaciones sobre la Biblioteca Joaquín V. González, el Inspector formulaba una sugerencia al Presidente de la CP:

\footnotetext{
${ }^{44}$ Expediente n. ${ }^{-326-L-18}$, Informe de inspección, 15/4/1942, CONABIP

45 Expediente n. ${ }^{\circ}$ 476-D-18, Informe de inspección, 7/7/1929, CONABIP.

${ }^{46}$ Ibíd., 7/7/1945.

${ }^{47}$ Expediente n. ${ }^{0}$ 177-L-33, Informe de inspección, 11/10/1935, CONABIP.

${ }^{48}$ Expediente n. ${ }^{\circ}$ 182-E-30, Informe de inspección, 13/08/1946, CONABIP.
} 
Complacido observé durante media hora el activo movimiento de la biblioteca, se trabaja allí con alegre entusiasmo (...) Opino que las autoridades de la biblioteca merecen un elogio de la Comisión Protectora y una donación de libros $(. . .)^{49}$.

\section{Las miradas sobre el material bibliográfico de las bibliotecas}

Cristalizadas en el ítem "observaciones" de los informes de inspección, hemos recogido las miradas de los/as inspectores/as acerca de los barrios donde funcionaban las bibliotecas, y acerca de sus dirigencias. Existe, sin embargo, otro campo, que condensa miradas disímiles de los/as funcionarios/as: aquel referido al "material bibliográfico", ítem que a su vez era ampliado, en muchos informes, en las "observaciones".

Respecto al "material bibliográfico", los/as inspectores/as debían consignar la cantidad de "volúmenes y folletos" de la biblioteca, elaborando una breve descripción de los mismos ${ }^{50}$ :

Posee 2000 volúmenes y 500 folletos, la mayoría a la rústica. Tiene el diccionario filológico, obras de Medicina, Sociología, Filosofía, Psicología, Comercio, Industria, y como todas las bibliotecas formadas por donaciones gran cantidad de novelas de toda índole ${ }^{51}$.

Esta descripción elaborada por Antelo sobre el "Material bibliográfico" de la Biblioteca Alborada, fue ampliada en el campo "observaciones":

Su mayor concurrencia está formada por vecindario en general y alumnas de los cursos que se dictan en el local, concurriendo muy pocos estudiantes, dada la índole de sus obras en las que hay una gran mayoría de novelas ${ }^{52}$.

${ }^{49}$ Expediente n. ${ }^{-}$264-L-33, Informe de Inspección, 6/7/1945, CONABIP.

${ }^{50}$ La clasificación "folletos" alude, en parte, a un nuevo formato popular, de muy bajo costo y tiradas masivas, consolidado hacia 1915, que en papel de baja calidad reproducía generalmente cuentos, novelas cortas, biografías, ensayos o incluso poemas. Ver: José Luis De Diego, "Un itinerario crítico sobre el mercado editorial de literatura en la Argentina". En La otra cara de Jano. Una mirada crítica sobre el libro yla edición (Buenos Aires: Ampersand, 2015), 49-78.

${ }^{51}$ Expediente n. ${ }^{326-L-18}$, Informe de inspección, 8/10/1935, CONABIP.

${ }^{52}$ Ibíd. 
El caso de esta biblioteca no constituía una excepción: instituciones ponderadas por la "honestidad de su administración" o su "buena atención", eran a menudo criticadas por "la índole de sus obras". Así, pese a que esta institución duplicó la cantidad de volúmenes en años sucesivos, según el informe del Inspector Albarracín, siete años después, el problema persistía:

Posee 4500 volúmenes y 1500 folletos y revistas. Obras diversas, diccionarios, textos primarios y secundarios, aunque no al día. Ciencias en general. Bellas artes. Filología e idiomas. Religión. Excesivo número de novelas. Elenco anticuado. De muy escasa renovación (...) Faltan textos y obras de consultas $(. . .)^{53}$.

Situación similar registraba la biblioteca Alejo Iglesias de Villa Elisa, la cual contaba con 1350 libros y "un buen número de folletos", que, según el mismo Inspector, conformaban un material "regular" compuesto por "obras generales, mucha literatura, pocas obras de consulta, algunos textos" ${ }^{54}$. Por su parte, la biblioteca Joaquín V. González, según la descripción de Antelo en 1935, poseía un material bibliográfico de casi mil libros compuesto por:

Diccionarios, obras de legislación, algo de ciencias en general, idiomas, obras históricas y como todas las bibliotecas formadas por donaciones, gran cantidad de novelas de toda índole ${ }^{55}$.

Dos años más tarde, la biblioteca poseía 400 libros más, pero Antelo volvía a señalar la presencia de "gran mayoría de literatura y obras poco seleccionadas" ${ }^{6}$. El mapa de bibliotecas atiborradas de novelas se completaba con la Mariano Moreno, que según Antelo poseía un catálogo de 1650 volúmenes, compuesto por "muy pocos textos, sociología, filosofía, algo de ciencias, teatro, poesías, obras históricas, en gran mayoría literatura y novelas" ${ }^{27}$. En tanto, la biblioteca del barrio Circunvalación, contaba con "1200 volúmenes, más de la mitad a la rústica" y "gran parte de literatura de toda índole" ${ }^{8}$. Por último, la biblioteca

${ }^{53}$ Expediente n. ${ }^{3}$ 326-L-18, Informe de inspección, 15/4/1942, CONABIP.

${ }^{54}$ Expediente n. ${ }^{\circ}$ 342-V-20, Informe de Inspección, 3/4/1928, CONABIP.

55 Expediente n. ${ }^{2}$ 264-L-33, Informe de Inspección, 11/10/1935, CONABIP.

${ }^{56}$ Expediente n. ${ }^{\circ}$ 264-L-33, Informe de Inspección, 29/10/ 1937, CONABIP.

${ }^{57}$ Expediente n. ${ }^{\circ}$ 476-D-18, Informe de inspección, 28/10/1937, CONABIP.

${ }^{58}$ Expediente n. ${ }^{\circ}$ 177-L-33, Informe de inspección, 11/10/1935, CONABIP. 
popular Alejandro Korn del Club Sporting poseía, según las observaciones de Albarracín:

Un elenco bibliográfico de escaso numerario y poco interesante. Faltan textos modernos (...) Concurren estudiantes del barrio, pero no hay para ellos libros que respondan a los nuevos programas de estudios. La Bca, que no cuenta con ningún subsidio especial, no posee, tampoco, recursos especiales para su adquisición ${ }^{59}$.

Desde luego, el señalamiento de los/as inspectores/as acerca de una mayoritaria presencia de "novelas de toda índole" en los estantes de las bibliotecas se vincula con las masivas tiradas -y la enorme circulación- de ediciones populares multiplicadas durante las décadas de 1920 y 1930 , al calor de la ampliación del público lector, la importación creciente de libros españoles y el surgimiento de emprendimientos editoriales locales como la Editorial Tor, Claridad y las colecciones de novelas semanales -en auge entre 1917 y $1925-{ }^{60}$. Con tapas llamativas, impresas en papel de baja calidad, un sinfín de novelas románticas, policiales, de terror o aventuras, podían adquirirse, por pocas monedas, en los puestos de diarios de la ciudad.

$\mathrm{Si}$ a este factor sumamos la presencia, reiterada en varios informes de inspección, de "donaciones" de libros, no parece ilógico que los/as vecinos/ as donaran, para formar la biblioteca de su barrio, estos libros de bajo costo y ágil lectura.

De igual modo, la atracción y popularidad de la literatura entre los/as usuarios/as de bibliotecas populares ha sido comprobada por historiadores que analizaron registros de préstamos: por ejemplo, Pasolini estimó que alrededor del 80\% del material prestado entre 1928 y 1945 por la biblioteca “Juan B. Justo de Tandil” correspondía al género “ficción”, en particular de los escritores Wast, Dumas, Zola y Salgari ${ }^{61}$. En el caso de la biblioteca "Juventud Moderna”, de Mar del Plata, estudiada por Quiroga (2003), fue corroborada la preferencia por títulos de Verne, Dumas, Leroux, Zola y Urales ${ }^{62}$.

${ }^{59}$ Expediente n. ${ }^{\circ}$ 170-L-16, Informe de inspección, 10/6/1943, CONABIP.

${ }^{60}$ Ver: Beatriz Sarlo, El imperio de los sentimientos. Narraciones de circulación periódica en la Argentina (1917-1927) (Buenos Aires: Catálogos editora, 1985).

${ }^{61}$ Pasolini, "Entre la evasión y el humanismo”, 373-401.

${ }^{62}$ Nicolás Quiroga, "Lectura y política. Los lectores de la biblioteca Popular Juventud Moderna del Plata (fines de los años treinta y principio de los cuarenta)". Anuario del IEHS, ${ }^{\circ}$ 19, (2003): 449-474. 
Con todo, las miradas de los/as inspectores/as de la CP acerca de la presencia de novelas "de toda índole" en las bibliotecas de La Plata, exhiben un evidente malestar, a juzgar por comentarios alusivos a su "excesiva cantidad" y a "obras poco seleccionadas”. Más aún, ese malestar se torna aún más explícito cuando se lo compara con otros informes que describen "elencos bibliográficos interesantes", "bien seleccionados" o de "cierta importancia" como en el caso de la biblioteca "San Martín” visitada por Albarracín:

Su material de lectura y consulta posee alguna importancia: libros de textos primarios y secundarios, pedagogía, literatura infantil, etc. Posee también una interesante colección de folletos y revistas sobre agricultura y ganadería ${ }^{63}$.

Para la Inspectora Antelo, la biblioteca popular “El estudiante”, perteneciente a la Sociedad Protectora de la Infancia, y administrada por sus asociadas, se caracterizaba por contar con un "material de lectura y consulta bien seleccionado", asistiendo a ella "gran cantidad de público, en su mayoría alumnos de las escuelas primarias y secundarias y de las distintas Facultades de la ciudad":

Posee 3500 volúmenes y 1000 folletos, muchos encuadernados. Tienen el diccionario enciclopédico, diccionarios en varios idiomas, obras de ciencias en general, de geografía en cantidad, filosofía, psicología, pedagogía, manuales de lectura, idiomas, religión, bellas artes, industrias, poesías, literatura más bien seleccionada y obras generales ${ }^{64}$.

Una descripción similar formulaba Antelo sobre el material bibliográfico de una de las primeras bibliotecas populares de la ciudad, la tradicional "Sarmiento", fundada en 1903 y radicada también en el centro de la ciudad, cuyo material de consulta y lectura -unos 18000 volúmenes- estaba

Muy bien seleccionado y sobre todo adaptado a las necesidades de los alumnos de las Escuelas Primarias, secundarias, y de los cursos universitarios, que forman gran parte de su público lector ${ }^{65}$.

\footnotetext{
${ }^{63}$ Expediente n. ${ }^{-387-L-37, ~ I n f o r m e ~ d e ~ i n s p e c c i o ́ n, ~ 11 / 06 / 1943, ~ C O N A B I P . ~}$

${ }^{64}$ Expediente n. ${ }^{\circ}$ 468-L-17, Informe de inspección, 7/10/1935, CONABIP.

${ }^{65}$ Expediente n. ${ }^{\circ}$ 221-L-14, Informe de inspección, 8/10/1935, CONABIP.
} 
En ambos casos, se trata de dos bibliotecas tradicionales y céntricas con muchos años de funcionamiento y protección de la $\mathrm{CP}$ en su haber, que poco tenían en común con aquellas nuevas fundadas, parafraseando a la propia inspectora, en los "deslindes" de la ciudad y que, a base de donaciones, engrosaban sus catálogos con novelas "de toda índole". En este sentido, constatamos que, tal como sugirió Planas, al equiparar la subvención de la CP a la capacidad de recaudación de las bibliotecas (ostensiblemente mayor en estos dos casos) se reproducían las desigualdades existentes entre ellas ${ }^{66}$. Más aún, la Biblioteca Sarmiento contaba, según Antelo, "con el decidido apoyo de los poderes provinciales y municipales”; y aún así, la Inspectora no dudaba en recomendarla "a la especial consideración de la Comisión Protectora" ${ }^{7}$.

En síntesis, las miradas de los/as inspectores/as indican una valoración positiva del material bibliográfico vinculado con la instrucción pública-textos de enseñanza primaria y secundaria, diccionarios, enciclopedias- y una valoración negativa de la "excesiva" cantidad de literatura "poco seleccionada". Por supuesto, la dicotomía entre los libros considerados "útiles" para el pueblo y los libros considerados "frívolos", "entretenidos"-y hasta "corruptores de las normas del buen gusto"68-, dista de ser exclusiva de estos/as funcionarios/as estatales, como, asimismo, de ser novedosa de este marco temporal y espacial. Antes bien, la historia cultural ha demostrado que la preocupación de parte de distintos poderes -monárquicos, eclesiásticos, corporativos, etc.- por las lecturas del pueblo existe, bajo distintas formas, desde la existencia misma de los libros ${ }^{69}$.

Por lo pronto, hacia 1914, quien fuera el Presidente de la CP, el ya mencionado Rodríguez, desaconsejaba a una biblioteca popular de Corrientes la compra de literatura de folletín y, en cambio, recomendaba “adquirir libros más útiles para la cultura popular"70. En 1938, el entonces Presidente de la CP, Echagüe, disertaba por Radio del Estado acerca de las colecciones bibliográficas de las bibliotecas populares en formación, estableciendo como primera necesidad la adquisición de "enciclopedias, diccionarios, obras de consulta y manuales",

66 Planas, "Libros, lectores y sociabilidades", 43-44.

${ }^{67}$ Expediente n. ${ }^{2}$ 221-L-14, Informe de inspección, 8/10/1935, CONABIP.

${ }^{68}$ Ver, por ejemplo, Paul Groussac, "La educación por el folletín”, La biblioteca, tomo VI, año II, (1897), pp. 315-316.

${ }^{69}$ Ver, por ejemplo: Robert Darnton, Censores trabajando. De cómo los Estados dieron forma a la literatura (México: Fondo de cultura económica, 2014).

${ }^{70}$ Expediente n. ${ }^{0}$ 615-M-11, Informe de Inspección, 22/08/1914, CONABIP. 
como segunda "lecturas infantiles", y solo después de atender estas dos, "ocuparse de periódicos y revistas"71. Esta escala de prioridades bibliográficas obedecía a que, según el propio Echagüe, las bibliotecas debían "cumplir su misión social" colaborando estrechamente con "todos los organismos culturales", pero sobre todo, "con los establecimientos educativos"72.

Así, las miradas de los/as inspectores/as sobre el material de las bibliotecas de La Plata revelan, por un lado, la adhesión a este lineamiento institucional de la $\mathrm{CP}$-ponderando en sus informes el material bibliográfico vinculado a la instrucción pública y criticando el excesivo número de novelas-; y por otro lado, las dificultades que en la práctica cotidiana tenían las bibliotecas populares para asumir aquella "misión social" que el Estado les asignaba. Las miradas sugieren, por lo tanto, un conjunto estimulante de contrapuntos entre las pretensiones del Estado - encarnado en la Comisión Protectora- en relación con la necesidad de que las bibliotecas populares contaran con un "catalogo útil" para fomentar la instrucción pública del pueblo - priorizando a los/as estudiantes de todos los niveles educativos, a adultos/as que asistían a los cursos gratuitos de las bibliotecas-; y los catálogos reales que desbordaron dichas pretensiones, conformados heterogéneamente por donaciones de vecinos/as, las compras decididas por los/as dirigentes de las bibliotecas y las partidas enviadas por la CP.

En cierto sentido, aquel "desborde" del material bibliográfico, materializado en una excesiva presencia de novelas, escenifica las hibridaciones generadas al interior de la "cultura letrada" a partir de la producción y reproducción en serie de bienes culturales - en este caso, libros- propios de la cultura de masas ligada al desarrollo capitalista del país ${ }^{73}$. Así, parafraseando a Jorge Luis Borges, los senderos de la cultura letrada se bifurcaban a paso acelerado, al calor de la producción masiva de literatura de bajo costo que circulaba en el mercado y poblaba los estantes de las nuevas bibliotecas de la ciudad.

${ }^{71}$ Pablo Echagüe, "Un mensaje a las bibliotecas populares", La nueva provincia, 6 de abril de 1938.

${ }^{72}$ Ibíd.

${ }^{73}$ Para un análisis conceptual de la cultura de masas remito a: Andreas Huyssen. Después de la gran división. Modernismo, cultura de masas, posmodernismo (Buenos Aires: Adriana Hidalgo Editora, 2006). 


\section{Consideraciones finales}

Durante las décadas de 1920, 1930 y 1940, el Estado -a través de la CP-y las asociaciones de la sociedad civil-mediante las bibliotecas- convergieron en los esfuerzos por difundir la lectura y la instrucción pública entre los vecinos/ as de los nuevos barrios que surgían al calor de la expansión de la ciudad.

Conforme aumentó el número de bibliotecas populares en el país, mediante los informes de inspección, la CP se garantizaba que estas cumplieran los requisitos oficiales para ser protegidas. Ante tal expansión, los largos e íntimos informes de la década de 1910 -tal como ilustraron los elaborados por Bortondieron paso a otros de tipo estandarizado, donde, en apariencia, quedaba poco espacio para los juicios y opiniones de los/as inspectores/as.

Decimos en apariencia, porque, según planteó nuestro recorrido, el ítem "observaciones" constituyó un espacio donde los/as funcionarios/as de la $\mathrm{CP}$ volcaron diversas percepciones acerca de los barrios, los dirigentes y los eclécticos materiales bibliográficos de las bibliotecas inspeccionadas.

Como se vio, las miradas de los/as inspectores/as solieron, al calor de detalladas descripciones, celebrar la acción social de las bibliotecas en los barrios humildes de la ciudad, así como la labor entusiasta de sus dirigentes. En el mismo acto, dichas miradas testimonian la distancia cultural existente entre el/la funcionario/a estatal y las "gentes modestas", "sin relieve intelectual" de los barrios visitados.

Por otra parte, si las miradas de los/as funcionarios/as fueron laudatorias cuando el material bibliográfico se enfocaba en la instrucción pública -diccionarios, enciclopedias, manuales escolares y obras de consulta-, toda vez que se encontraron frente a estantes colmados de libros rústicos y folletos, en su mayoría novelas, proliferaron las miradas despectivas.

Disímiles miradas habilitadas, en parte, debido a que las bibliotecas populares inspeccionadas, tal como se desprende de los informes, funcionaban con un alto grado de autonomía, por lo general, en salas austeras, equipadas "con mueblaje sencillo, pero apropiado" (armarios o estanterías, mesas y sillas), atendidas por bibliotecarios honorarios (en general, miembros de la comisión) y sostenidas económicamente por las cuotas de los/as asociados/as, veladas y festivales. Esta situación las hacía tropezar con usuales dificultades económicas, frente a las cuales la capacidad de adquirir libros se veía resentida, al tiempo que la protección de la $\mathrm{CP}$ se tornaba indispensable (tanto para recibir donaciones de ejemplares, como para comprarlos a menor costo) y se recibían donaciones de libros del vecindario. 
Este alto grado de autonomía respecto de la CP se deduce también de la discontinuidad de los informes a lo largo de los años, y del hecho de que aunque en ciertos casos estos contuvieron observaciones desfavorables de los/ as inspectores/as -procediéndose a la típica sanción de suspender el envío de libros-, estas no atentaron contra la continuidad de la protección en ninguna de las bibliotecas populares analizadas.

En definitiva, los informes no solo nos permiten ampliar nuestros conocimientos sobre las bibliotecas populares sino también comenzar desagregar los términos de una relación poco explorada por la historiografía: aquella establecida entre una institución cultural como la Comisión Protectora y las bibliotecas populares argentinas fuertemente expandidas en estas décadas de entreguerras ${ }^{74}$; relación sobre la cual será preciso indagar en futuras aproximaciones, pero sobre la cual los casos aquí abordados comienzan a arrojar vestigios de luz.

\section{Referencias bibliográficas}

\section{Fuentes primarias}

\section{Archivos}

Expedientes de Bibliotecas Populares del Partido de La Plata de la Comisión Nacional de Bibliotecas Populares (CONABIP): Exp no 170-L-16; Exp. no 326-L-18; Exp.

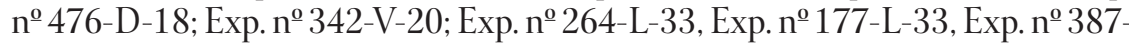
L-37, Exp. nº 182-E-30, Exp. no 221-L-14, Exp. nº 468-L-17, Exp. nº 615-M-11.

\section{Impresas}

Memoria de la Comisión Protectora de Bibliotecas Populares de los años 1915 y 1916, Buenos Aires: Talleres Gráficos de L.J. Rosso y Cía, 1917.

\section{Periódicas}

Diarios: El Argentino, El Diario y La Nación.

\section{Fuentes secundarias}

Barrancos, Dora. La escena iluminada. Ciencia para trabajadores, 1890-1930. Buenos Aires: Plus Ultra, 1996.

Burke, Peter. Visto y no visto. El uso de la imagen como documento histórico. Barcelona: Crítica, 2005.

Darnton, Robert, Censores trabajando. De cómo los Estados dieron forma a la literatura. México: Fondo de cultura económica, 2014.

${ }^{74}$ Una excepción es el ya citado trabajo de Fiorrucci, "La cultura, el libro y la lectura bajo el peronismo", 543-556. 
De Certeau, Michel.Lainvención de lo cotidiano 1.Artes de hacer. México: Universidad Iberoamericana, 2008.

De Diego, José Luis. La otra cara de Jano. Una mirada crítica sobre el libro y la edición. Buenos Aires: Ampersand, 2015.

De Privitellio, Luciano, Vecinos y ciudadanos. Política y sociedad en la Buenos Aires de entreguerras. Buenos Aires: Siglo XXI, 2003.

Echagüe, Pablo, "Un mensaje a las bibliotecas populares", La nueva provincia, 6 de abril de 1938.

Fiorrucci, Flavia, "La cultura, el libro y la lectura bajo el peronismo: el caso de la Comisión de bibliotecas populares”. Desarrollo Económico 48, n. ${ }^{\circ}$ 192, (enero-marzo, 2009): 543-556.

Frydenberg, Julio. Historia social del futbol: del amateurismo a la profesionalización. Buenos Aires: Siglo XXI, 2013.

González, Ricardo, "Lo propio y lo ajeno. Actividades culturales y fomentismo en una asociación vecinal. Barrio Nazca (1925-1930)”. En Mundo urbano y cultura popular. Estudios de historia social, compilado por Diego Armus. Buenos Aires: Sudamericana, 1990.

Groussac, Paul, “La educación por el folletín”, La biblioteca, tomo VI, año II, (1897): 315-316.

Gutiérrez, Leandro y Luis Alberto Romero. Sectores populares, cultura y política. Buenos Aires en la entreguerra. Buenos Aires: Siglo Veintiuno Editores, 2007 [1995].

Huyssen, Andreas. Después de la gran división. Modernismo, cultura de masas, posmodernismo. Buenos Aires: Adriana Hidalgo Editora, 2006.

Pasolini, Ricardo. "Entre la evasión y el humanismo. Lecturas, lectores y cultura de los sectores populares: la biblioteca Juan B. Justo de Tandil, 1928-1945”. Anuario del IEHS, n. ${ }^{\circ} 18$ (1997): 449-474.

Planas, Javier. Libros, lectores y sociabilidades de lectura. Una historia de los orígenes de las bibliotecas en la Argentina. Buenos Aires: Ampersand, 2017

Quiroga, Nicolás, “Lectura y política. Los lectores de la biblioteca Popular Juventud Moderna de Mar del Plata (fines de los años treinta y principio de los cuarenta)". Anuario del IEHS, n.․ 18, (2003): 449-474.

Roldán, Diego P. La invención de las masas. Ciudad, corporalidades y culturas. Rosario, 1910-1945. La Plata: Universidad Nacional de La Plata, 2012.

Sarlo, Beatriz, El imperio de los sentimientos. Narraciones de circulación periódica en la Argentina (1917-1927). Buenos Aires: Catálogos editora, 1985. 